Recebido: 30/08/2017

Aprovado: 08/01/2018

\title{
O uso de imagens na história: Transformações do espaço urbano de Tefé a partir de sua iconografia (1960-1980)
}

Fabielle Ribeiro Esperança*

Resumo: $O$ artigo em tela tem como objeto central analisar as transformações do espaço urbano na cidade de Tefé-AM entre as décadas de 1960 a 1980 pautando-se no uso de ferramentas analíticas oferecidas pela História Social em suas Múltiplas Formas. O uso de imagens, bem como a tentativa de ampliação de pesquisas sobre as modificações do tecido urbano nas cidades do interior da Amazônia vem ampliando as possibilidades de pesquisas, bem como a utilização de novas fontes. A questão que se coloca é: como à luz da História Social e dos estudos sobre cidade podemos compreender as transformações do espaço urbano no interior do Amazonas a partir do uso de imagens? Este artigo é resultado de pesquisas realizadas na seção de documentação da Rádio Educação Rural de Tefé, onde encontram-se uma quantidade massiva de imagens em diversos momentos históricos. O presente texto encontrasse dividido em quatro partes: na primeira Imagens da cidade busca-se traçar um esboço e uma crítica as fontes bem como sua vinculação com a temática. Na segunda cidade na história pretende-se estabelecer um breve comentário de que forma o tema cidade é abordado pelos historiadores. Na terceira $A$ história das imagens é elaborado uma breve exposição dos diferentes tipos de abordagens de imagens enquanto fontes. Na quarta Tefé e seus bairros nos anos 1960 a 1980 estabelecemos algumas análises sobre o crescimento da cidade.

Palavras-chaves: História e Cidade; História do Amazonas e Tefé

Abstract: The article on screen has as its central object to analyze the transformations of the urban space in the city of Tefé-AM between the decades of 1960 to 1980 guiding in the use of analytical tools offered by the Social History in its Multiple Forms. The use of images, as well as the attempt to expand research on the modifications of the urban fabric in the cities of the interior of the Amazon, has expanded the possibilities of research, as well as the use of new sources. The question that arises is: how in the light of Social History and the studies about city can we understand the transformations of the urban space in the

\footnotetext{
* Autora é graduada em História pela Universidade do Estado do Amazonas. Atualmente faz especialização em metodologia do ensino de história e geografia. Atua como professora na rede pública municipal (SEMED) na cidade de Tefé/AM.
} 
interior of the Amazon from the use of images? This article is the result of research carried out in the documentation section of Tefé Rural Education Radio, where a massive amount of images are found at various historical moments. The present text is divided into four parts: in the first Images of the city, a sketch and a critique of the sources as well as their connection with the theme is sought. In the second city in history we intend to establish a brief comment on how the theme city is approached by historians. In the third one The history of the images is elaborated a brief exposition of the different types of approaches of images as sources. In the fourth Tefé and its neighborhoods in the years 1960 to 1980 we established some analysis on the growth of the city.

Keywords: History and City; History of Amazonas; Tefé. 


\section{Imagens da Cidade}

Tefé cresceu as margens do rio do mesmo nome. Suas imagens, como a que chegue abaixo, apresentam prédios, praças, igrejas, que demonstram suas transformações com o passar dos anos. A partir de imagens coletadas nos arquivos locais observam-se significativas mudanças no espaço urbano deste local. Fotos de casas, prédios oficiais, locais públicos ou privados que formam a memória social dos indivíduos que nasceram ou simplesmente moram na cidade apontam claramente uma alteração no espaço urbano da cidade principalmente entre os anos de 1960 e 1980.

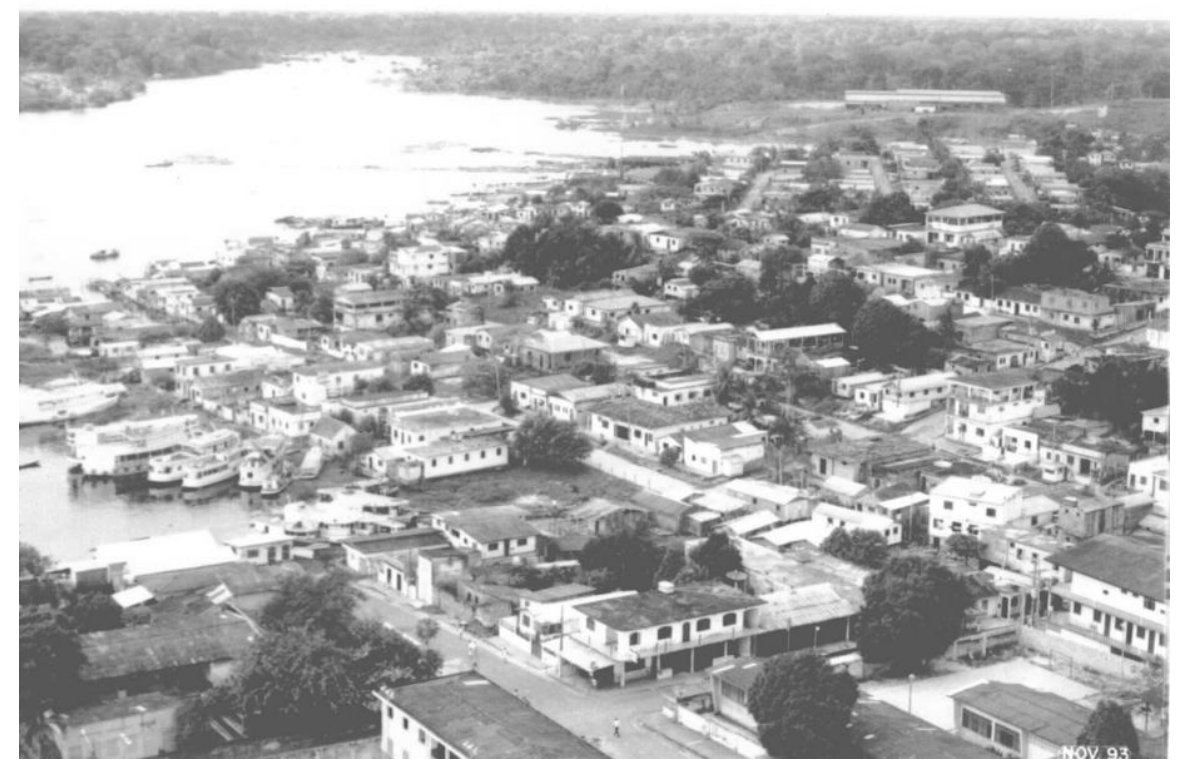

Imagem 1 visão panorâmica da cidade de Tefé-Am anos 60- Foto do Arquivo da Rádio Rural - Seção de documentação.

O espaço urbano que se modifica constantemente é captado ao longo do século XX a partir das imagens dos principais pontos que constituem o seu aparelho urbano. Compreender tais transformações de Tefé, a partir da coleta e análise de fotos do município, nos auxilia a descrever e compreender o processo de formação do espaço urbano de ícones (Seminário, Catedral de Santa Teresa, etc) que constituem a memória social a respeito das transformações ocorridas na cidade. Memorialistas como Raimunda Gil Schaeken (1997) e Protásio Pessoa (1997) descrevem a importância da presença da igreja católica, bem como de suas missões para o crescimento e urbanização (construção de prédios) na cidade de Tefé. As imagens

\section{Fistortorias}


abaixo, seja do seminário São José ${ }^{1}$ quanto da Catedral de Santa Teresa tornaram-se símbolos da cidade.

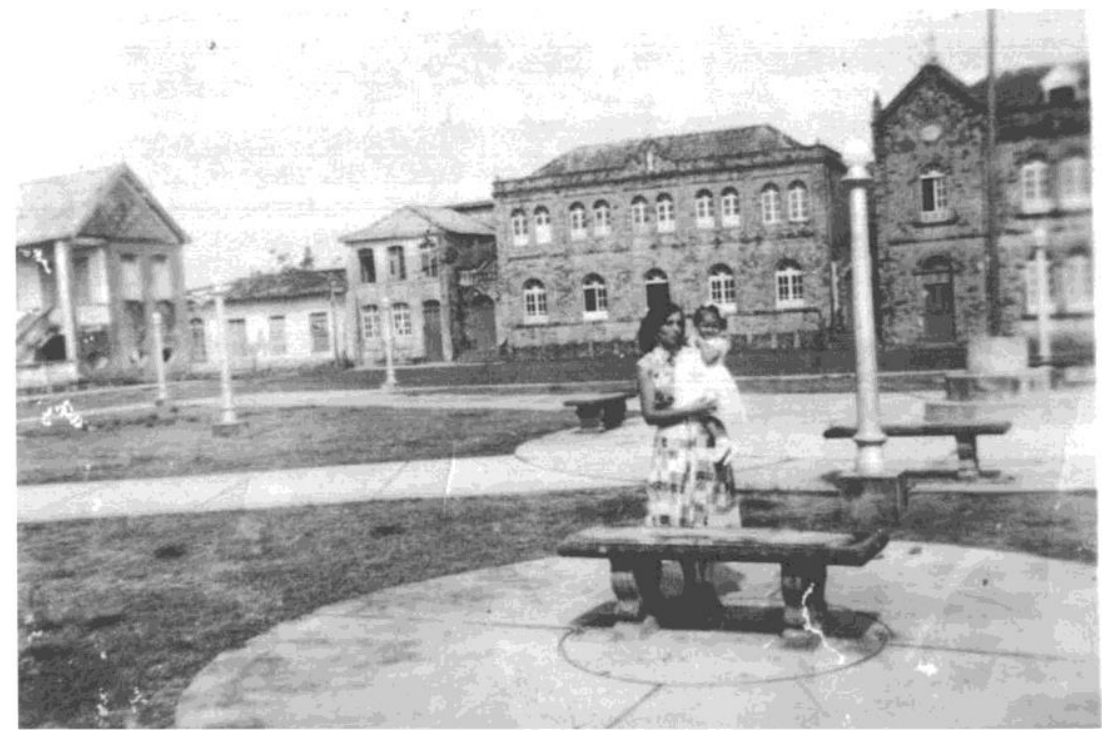

Imagem 2 Praça do Seminário de Tefé-Am anos 60- Foto do Arquivo da Rádio Rural - Seção de documentação.

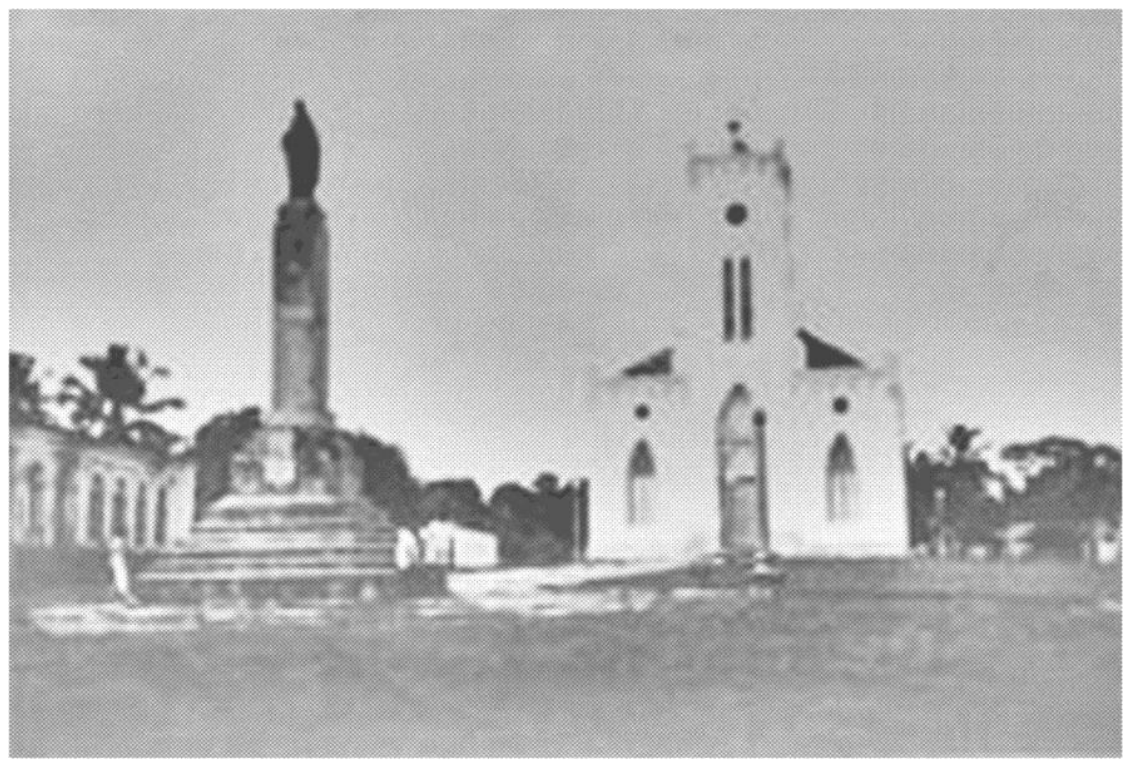

Imagem 3 Catedral de Santa Teresa em Tefé-Am anos 60- Foto do Arquivo da Rádio Rural Seção de documentação.

\footnotetext{
1 Monsnhor Barrat bispo da Prefeitura apostólica então responsável pela missão dos Espiritamos na cidade de Tefé conclui em 1935 as obras em estilo holandês do Seminário, iniciadas em 1919 para abrigar as atividades do Externato São José. Cf. Pessoa, 2005, p.75-77; Queiroz 2015.
}

\section{Finstonerias}


Pesavento (1995) afirma que em termos teórico-metodológicos os estudos da chamada História Cultural estão na ordem do dia na historiografia mundial. Segundo a autora: "Estaríamos diante de uma das correntes centrais do novo paradigma que se propõe substituir o esfacelamento do conjunto de ideias e certezas herdadas do século XIX que se encontra em propalada crise nos tempos atuais." (p. 279).

A História Cultural, para Pesavento, baseada em Hunt, é entendida como desdobramento da História Social e esta:

(...) se apresentava como a vertente resultante da confluência das historiografias inglesa e francesa, a chamada nova história cultural se encontra difundida pela Alemanha e Estados Unidos, sem falar em tradições mais antigas como a Itália. (1995:279).

O conceito de História Cultural ${ }^{2}$, ou melhor, o entendimento acerca do que se trata, nas palavras de Pesavento:

Entendemos a história cultural não como uma 'virada de mesa' com relação a pressupostos teórico-metodológicos, mas como uma nova abordagem, ou um novo olhar que se apoia sobre as análises já realizadas (...) Neste sentido, a história cultural realmente vem se somar ao conhecimento acumulado, sem voltar as costas a uma matriz teórica fruto de uma reflexão cumulativa (1995: 280).

A História Cultural, para Pesavento oferece o arcabouço teórico sob o qual se pode resgatar a cidade a partir das representações, tentando entender o que a autora classifica como "fenômeno urbano", considerando a cultura como uma rede de significados socialmente estabelecidos.

Sandra Pesavento (1995) alerta ainda que o elemento catalisador do pensamento contemporâneo são os debates em torno da chamada história cultural, principalmente os relacionados ao sistema de ideais-imagens que compõem o imaginário social. A autora entende a história cultural como uma nova abordagem ou um novo olhar que se apoia sobre analises já realizadas.

Pesavento afirma que:

\footnotetext{
${ }^{2}$ Sandra Pesavento aborda os aspectos teórico-metodológicos e historiciza o surgimento desta corrente na historiografia francesa da chamada História Cultural na obra História \& História Cultural 2012.
} 
Pensar o social através de suas representações é, ao nosso ver, uma preocupação contemporânea (...) baliza pela crise dos paradigmas explicativos da realidade que pôs em xeque a objetividade e racionalidade das leis cientificas e racionalidade das ciências humanas. (1995: 280).

Atingir o "real" através das relações, a partir das representações, segundo Pesavento (1995) implica partir de um determinado referencial teórico. Para Chartier (1991) toda reflexão metodológica enraíza-se numa pratica histórica particular. Chartier (1991), em consonância com Pesavento, afirma que a noção de representação coletiva faz a partir de um retorno a Durhkeim e Mauss e consequentemente autoriza uma articulação do conceito de mentalidade com três modalidades de relações com o mundo social:

De acordo com Chartier a noção de representação é central para a sua concepção de história cultural, que se baseia, segundo Pasavento (1995) na correlação entre práticas sociais e representações.

Para Pesavento (1995): “(...) a cidade é o espaço por excelência para a construção destes significados, expressos em bens culturais. Nosso intento é, pois, resgatar a cidade como real através da 'leitura da cidade', ou de suas representações.” (p. 281).

\section{Cidade na história}

A cidade, segundo Pesavento (1995) é uma realização muito antiga e consequentemente marca sua presença na História. Mas é sob o advento do capitalismo que se impõe o que a autora denomina de "questão urbana".

A respeito do tema Cidade, Bresciani (1998) afirma que as cidades são antes de tudo uma experiência visual, lugar saturado de significações acumuladas através do tempo, enfim uma produção social.

Bresciani afirma que existem descrições extensas das cidades presentes nos escritos dos viajantes, contudo:

(...) nos dois últimos séculos, imagens e representações elaboradas sobre as cidades têm lhes conferido avaliações nem sempre positivas. Edmund Burke, (...) considerou, no final do século XVIII, que "no estado de rude natureza não é possível existir um povo'. Faz-se necessária, prossegue, a ideia de corporação, um constructo, portanto algo totalmente artificial, uma ficção legal, ou seja, o contrato que forma a sociedade acordado em comum consentimento." (1998: 240).

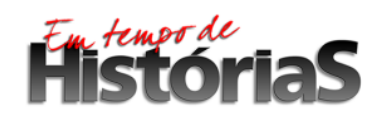

(PPGHIS/UnB) №. 31, Brasília, Ago - Dez 2017 ISSN 2316-1191 
Esta imagem persistente, segundo Bresciani, conviveu no século XVIII com avaliações negativas e positivas expressas no período a respeito da cidade. Já para o século XIX, a autora alerta que a opinião expressa fora reforçada por homens cultos do chamado Século das Luzes, que viam na cidade a dinâmica da civilização.

Bresciani esclarece que se forja uma concepção onde a cidade era vista como dependente do campo, e cheia de artificialidade. Para a autora:

Essa concepção perdura, com traços acentuados e muitas vezes radicalmente contrastantes, como contraponto e referência das formas de vida na moderna sociedade industrial. Assim, se autores críticos das grandes cidades, entre eles Friedrich Engels, nelas identifica, (...) a relação perversa de criação da riqueza diretamente proporcional ao aumento da pobreza miserável, essa duplicidade é reiterada por pensadores importantes da virada do século XIX para o XX, ao aceitarem o desafio de avaliar o mal-estar inerente ao mundo civilizado. (199: 241).

Conforme o mencionado por Bresciani (1998), Pesavento (1995) afirma que já existe um significativo conhecimento acumulado em termos de estudos urbanos que nos foi legado pela História econômica e social, que segundo esta última era voltada para as origens e desenvolvimento do capitalismo e da sociedade burguesa e que tinha na cidade o seu espaço privilegiado de análise.

A História estuda o imaginário social, os sistemas simbólicos, imagens e representações coletiva. Neste tópico iremos estuda a cidade através das representações iconográficas e de que maneira autores diferentes abordam a cidade enquanto temática de pesquisa.

Para Geertz (1981) a cidade é o espaço por excelência para a construção destes significados, expressos bens culturais, resgatar a cidade como real através da "leitura de cidade" ou de representações (PESAVENTO 1995).

Para Sandra Pesavento (1995) a cidade é como se sabe, uma realização muito antiga. Ela marca sua presença na história, através daqueles elementos que assinalam o advento do que se considera civilização o capitalismo se impõe a questão urbana. Existiu um processo econômico que desenhou o crescimento populacional das cidades exemplos concentração populacional, migração rural etc.

Como afirma Pinol (1991), a história urbana não teve a mesma importância e/ou dimensão em todos os países do mundo ocidental, cabendo à Grã-Bretanha e os Estados Unidos o pioneirismo nesta área (PESAVENTO 1995).

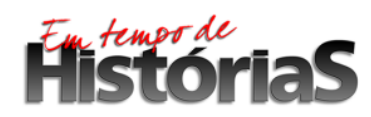

(PPGHIS/UnB) No. 31, Brasília, Ago - Dez 2017 ISSN 2316-1191 
No Brasil varia por região os estudos sobre as análises iconográficas, as representações constituídas sobre o urbano podem também, corresponder ou não aos códigos iniciais e às intenções dos seus construtores (PESAVENTO 1995).

A cidade teria que ser projetada por arquitetos para se ter uma organização desejada Marcel Roncayolo (1995) vê a cidade como representação ou conjunto de representação um sistema de ideias, mais ou menos coerente, daqueles que fazem parte a projetam, discutem e executam (PESAVENTO 1995).

Traduzir a cidade por imagens implica em um fenômeno de percepção que envolve a logicas sociais. Para Monlibert (1995) estes processos implicam julgamentos sociais, vivências, lembranças e posições estéticas em cuja base se encontra a operação prática do habitus de que fala Bourdieu. (habitus “aquisição ou capital”) (PESAVENTO 1995).

Homens comuns como pintores e fotógrafos tem uma sensibilidade de elabora uma representação das cidades com fotografias ou pinturas bem feitas algumas obras de artes do urbano.

\section{A história das imagens}

A fotografia se tornou a pouco tempo fonte de pesquisa pois antes só documentos escritos eram confiáveis. Foi com a revolução documental na década de 1960 a fotografia começou a ganha lugar na pesquisa em História.

Até hoje há um certo preconceito em utilizar a fotografia para pesquisa. Para Kossoy (1989), dois movimentos levam a isso: um aprisionamento à tradição escrita e as próprias dificuldades que o pesquisador encontra, entre as quais pode-se falar das questões envolvendo a realidade fotográfica, das diferentes visões originas pelas diferentes formações dos pesquisadores e da necessidade de outras fontes para complementar a pesquisa (MENEZES 2012).

A fotografia tem maneira diferente do documento escrito a imagem serve como vitrine do texto abrigando informações e comentários do documento escrito. Segundo Kossoy (1989), quanto a utilização, e correto dizer que imagens fotográficas de outras épocas, na medida em que identificadas e analisadas objetiva e sistematicamente a parti de metodologias adequadas, se constituem em fontes insubstituíveis para a reconstituição histórica dos 
cenários, das memorias de vida, de fato do passado centenário como do mais recente (MENEZES 2012).

Segundo Cardoso e Maud, num período da historiografia quando a máxima seguida era a história faz-se com textos, aquela posição não teve maior impacto. Foi com a escola dos Annales no século XX com seus fundadores Marc Bloch e Lucien Febvre que surgiu o uso das imagens como fontes de pesquisa.

De lá pra cá, tanto a noção de documento quando de texto continuaram a ampliar-se agora todo vestígio do passado são considerados matéria para o historiador. Dessa forma, novos textos, tais como pintura, o cinema, a fotografia etc., foram incluídos no elenco de fontes dignas de fazer parte da história e passiveis de leitura por parte do historiador. (Cardoso e Maud, 1997: 402)

Conforme Cardoso e Maud trabalhar com material fotográfico surpreende, pois do papel em branco surge à imagem revelada por humanos, líquidos de composição certa. Lembranças passadas, memorias da sua vida entre outras coisas existem na fotografia.

Ao historiador, a fotografia lança um grande desafio: como chegar aquilo que não foi revelado pelo olhar fotográfico. Tal desafio impõe-lhe a tarefa de desvendar uma intricada rede de significações, cujos elementos - homens e signos - interagem dialeticamente na composição da realidade. Uma realidade que se formula a partir do trabalho de homens como produtores e consumidores de signos; um trabalho cultural, cuja compreensão é fundamental para se operar sobre esta mesma realidade. (CARDOSO e MAUD, 1997: 405)

A fotografia mesmo sendo um circuito complicado de entender pode ser considerada uma pista entre seus variados códigos tem um modo conotativo que se insere as formas de agir no contexto que estão colocadas com mensagem.

Cardoso e Maud (1997) afirma que a imagem fotográfica compreendida como documento revela aspectos da vida material de um determinado tempo do passado de que a mais detalhada descrição verbal não daria conta. Ainda segundo os autores neste sentido, a imagem fotográfica seria tomada como índice de uma época, revelando, com riqueza de detalhes, aspectos da arquitetura, indumentária, formas de trabalho, locais de produção etc.

\section{Filstorónias}


Uma leitura que ultrapassa a avaliação da fotografia como mera ilustração, contudo, ainda se restringe à avaliação da foto.

\begin{abstract}
A transmissão de eventos do passado ao historiador pela mensagem fotográfica, no entanto deveria limita-se ao âmbito da comunicação pura e simples. É, justamente, a busca da lógica de tais elementos num determinado tempo e espaço que faz com que adquiram um significado que tanto pode informar aspectos matérias, como foi indicado acima, quanto revelar uma imagem/monumento: aquilo que, no passado, a sociedade queria perenizar de si mesma para o futuro. (CARDOSO e MAUD, 1997: 406)
\end{abstract}

Vista como monumento a fotografia pede do historiador um julgamento que supera o campo descritivo. Para os autores neste caso, ela é agente do processo de criação de uma memória que deve promover tanto a legitimação de uma determinada escolha quanto, por outro lado, o esquecimento de todas as outras.

Já a fotografia como mensagem pode ser incluída com analise dos estudos das linguagens no conjunto de uma abordagem semiótica. Segundo Rossi-Landi, é importante perceber que existem formas de comunicação mais profundas e menos advertidas do que as verbais; e que mesmo sem saber emitimos mensagens não verbais.

Durante o século XX quando as imagens começaram a aparecer nos livros feitos pelos historiadores criou-se uma nova metodologia para aproximar os documentos iconográficos dos pesquisadores.

Ulpiano Menezes (2012) afirma que a visualidade foi sendo percebida como componente importante nos domínios científicos à medida que a imagem visual e suas diversas modalidades foi penetrando na contemporaneidade. Ainda segundo o autor Gottfried Boehm não a como normatiza critérios e abordagens a respeito do uso da imagem visual.

Para compreender a fotografia como fonte histórica é importante leva em conta os usos sociais da foto ao longo dos séculos XIX e XX quando se consolidaram como documentos importantes de pesquisa (LIMA e CARVALHO 2011).

Menezes (2012) afirma que é fundamental que o historiador rompa as limitações nas quais se reduz a imagem a penas como documento visual utilizando-a a mesma para classificações e leituras iconográficas. De acordo com o autor: "É igualmente crucial que o pesquisador se familiarize com as inúmeras variáveis que definem a natureza da imagem e a

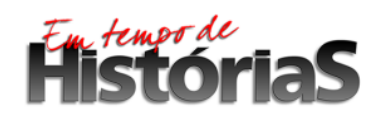


multiplicidade de significados e papeis que ela pode assumir historicamente.” (MENEZES ,2012: 243).

De acordo com Lima e Carvalho (2011) quando a fotografia ingressou no mercado em versões técnicas e variadas entre os anos de 1839 e 1850, rapidamente nelas se identificou a capacidade de atender as mais diferentes demandas sociais. A rapidez da produção em série se tornara requisitos básicos numa sociedade com crescente industrialização. $\mathrm{O}$ crescimento dos seguimentos inéditos e suas expectativas de ascensão incentivarão novas formas de representação de identidade e distinção que estavam sem sintonia com os esforços de grupos sociais que transformaram a fotografia num grande negócio. Para as autoras a fotografia foi pouco a pouco substituindo a pedra litográfica.

Conforme assinala Menezes (2012) de longe abordagem mais corrente entre os historiadores a respeito da análise de imagens visuais está pautada em Erwin Panofsky, a iconográfica. Panofsky a partir da segunda metade do século XX privilegiava o significado das imagens a iconografia em sintonia com a semiótica. Para o autor, ambas compartilham o tratamento da imagem predominantemente como um suporte sígnico e tendem a verificar neles propriedades internas que são estáveis.

O termo iconografia para Menezes (2012) em sua raiz etimológica pressupõe um papel descritivo e classificatório. Reduzida a sua versão mais simples o autor afirma que a iconografia busca identificar a imagem 'a significação interna de significações externas' (Bohem, apud Menezes, p. 244). Já a iconologia implica, ainda de acordo com o autor, um passo adiante na elaboração de teorias, generalizações e atualmente é este segundo termo que possui uso mais ampliado e superou a iconografia.

No século XX surgiu várias obras falando sobre as imagens uma delas e a de Ewin Panofsky em seu livro Significados nas artes visuais em 1995 traz uma proposta com três estados do estudo da fotografia.

O primeiro- o pré-iconografico - é basicamente descritivo e se fundamenta na experiência cotidiana complementada pelo conhecimento de repertórios para definir informação factual, bem como expressivas. O segundo nível é o da analise iconográfica propriamente dita. Aqui, trata-se das significações secundarias, das convenções, formulas, motivos artísticos, temas e conceito. O último nível é o mais complexo, o da interpretação iconológica, à procura de uma espécie de "mentalidade de base". (MENEZES, 2012:244) 
Segundo o autor a três observações cautelares que merecem atenção. Antes de mais nada, há um engano quando se imagina a natureza visual do documento a qual responde pela natureza visual do problema histórico que se quer pesquisa.

\begin{abstract}
A fotografia foi uma das primeiras modalidades de imagem a ter seu caráter artefatual reconhecido, por causa das implicações facilmente apreensíveis de contexto, usos e práticas - e significações. Considerando apenas o contexto, uma foto 3 x 4 em um documento de identidade é diversa da mesma imagem em uma carteira, que simboliza a lembrança de uma pessoa querida. Ainda a mesma imagem em um porta-retratos no escritório cauciona o reconhecimento de valores sociais envolvendo, por exemplo, a família. Novamente essa imagem, agora na parede de uma instituição, acrescenta valores de memorial e continuidade institucional. $\mathrm{E}$ assim por diante: em um museu, no jornal, em um cartaz etc. (MENEZES, 2012: 254)
\end{abstract}

Existe uma associação entre imagem e memoria que é chamada de natural. Segundo Menezes com efeito, a imagem visual, na sua condição de conteúdos de consciência sensível, concreta (Mayerson), parece dotada da capacidade de fixar estados de coisas - o que, em última analise, significa a aceitação da natureza fenomênica do real.

Em janeiro de 1986 lançaram um projeto iconográfico na fundação Osvaldo Cruz um acervo de muita importância contentos diversos tipos de fotos as autoras Albuquerque e Klein ressaltam o objetivo desse projeto que é recuperação do debate que envolve a fotografia como registro referencial.

O pesquisador tem um grande trabalho para fazer uma leitura de reflexão de suas fontes tem que formular perguntas para fazer ao documento e ver si vale apena mesmo estuda a imagem escolhida.

Mauricio Lissovsky (1983) é categórico ao afirmar que o pesquisador não dispõe de um método que lhe permita prescindir da subjetividade da perspectiva do fotografo. Segundo ele, no processo de produção a fotografia tem-se que combinar três elementos: conteúdo da imagem; o fotografo e a tecnologia utilizada (MENEZES 2012).

\title{
Tefé e seus bairros nos anos 1960 a 1980
}

Localizada no médio Solimões a cidade de Tefé, ao longo de sua história, primeiro como uma das missões jesuíticas do Padre Samuel Fritz, em seguida como núcleo missionário

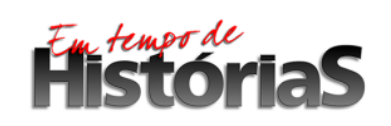


carmelita Frei André da Costa, posteriormente como vila de Ega já em período colonial, ou como a cidade sede da comarca do Solimões da Província do Amazonas, já no século XX, como polo de atração de migrantes em virtude da produção de borracha, a cidade passa por constantes transformações, seja em seu espaço geográfico (que dá origem em seus desmembramentos a todas as cidades atuais do médio e alto Solimões), seja em sua atração por personagens sociais diferenciados.

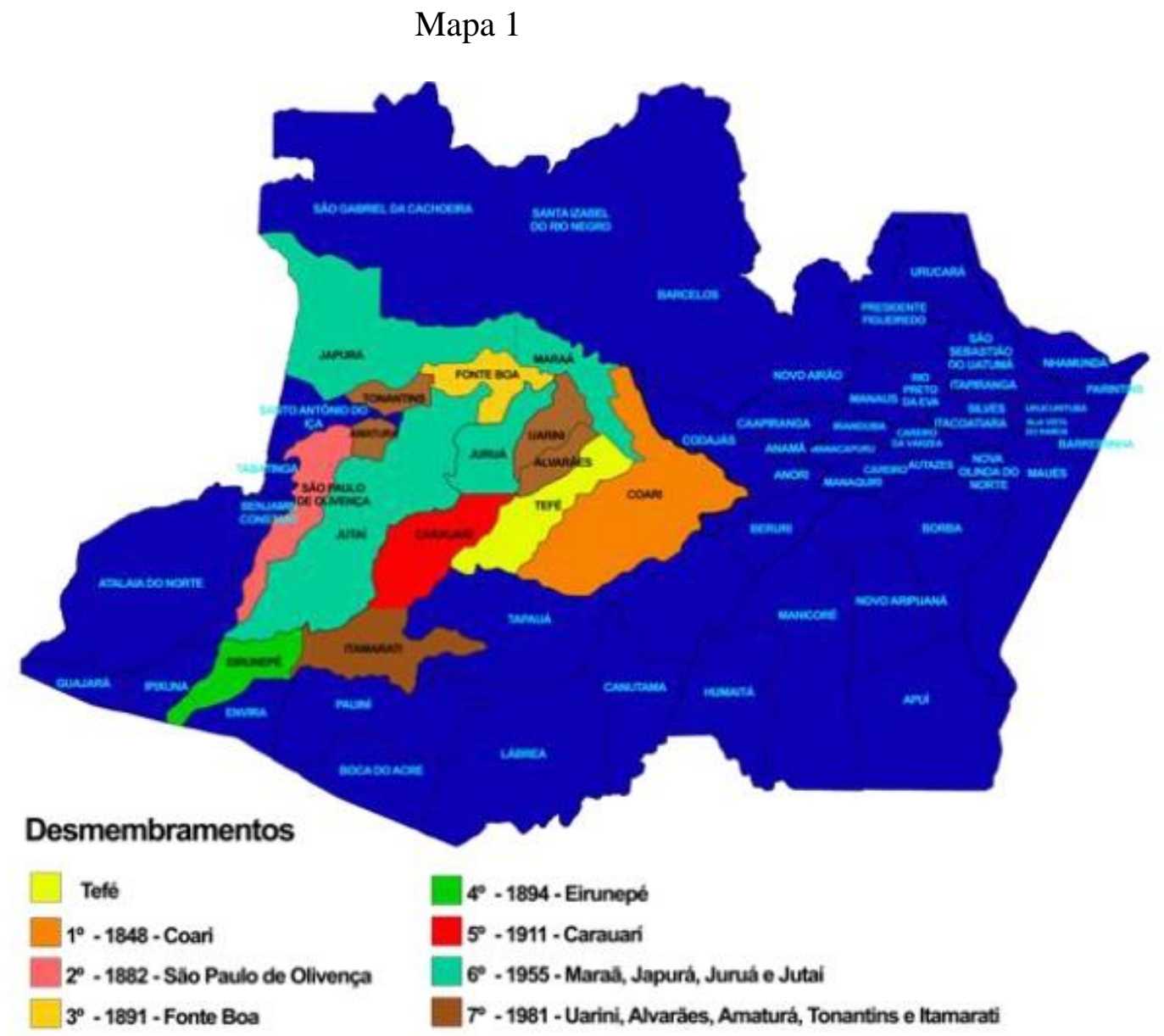

Mapa 1 desmembramento de Tefé-Am fonte: QUEIROZ, Kristian .Centralidade periférica e integração relativizada: uma leitura de Tefé no Amazonas. 2015

No fim dos anos de 1960 o então prefeito de Tefé Manuel Armando Retto concede título definitivo aos posseiros da área urbana e rural, que haviam construído casas ou beneficiado as posses. Os bairros construídos neste período foram Monte Castelo, Santo

\section{Fististornias}


Antônio, Juruá I e II, Santa Rosa e Olaria. Além disso foram distribuídas terras da Campina e praça Isidoro Praia.

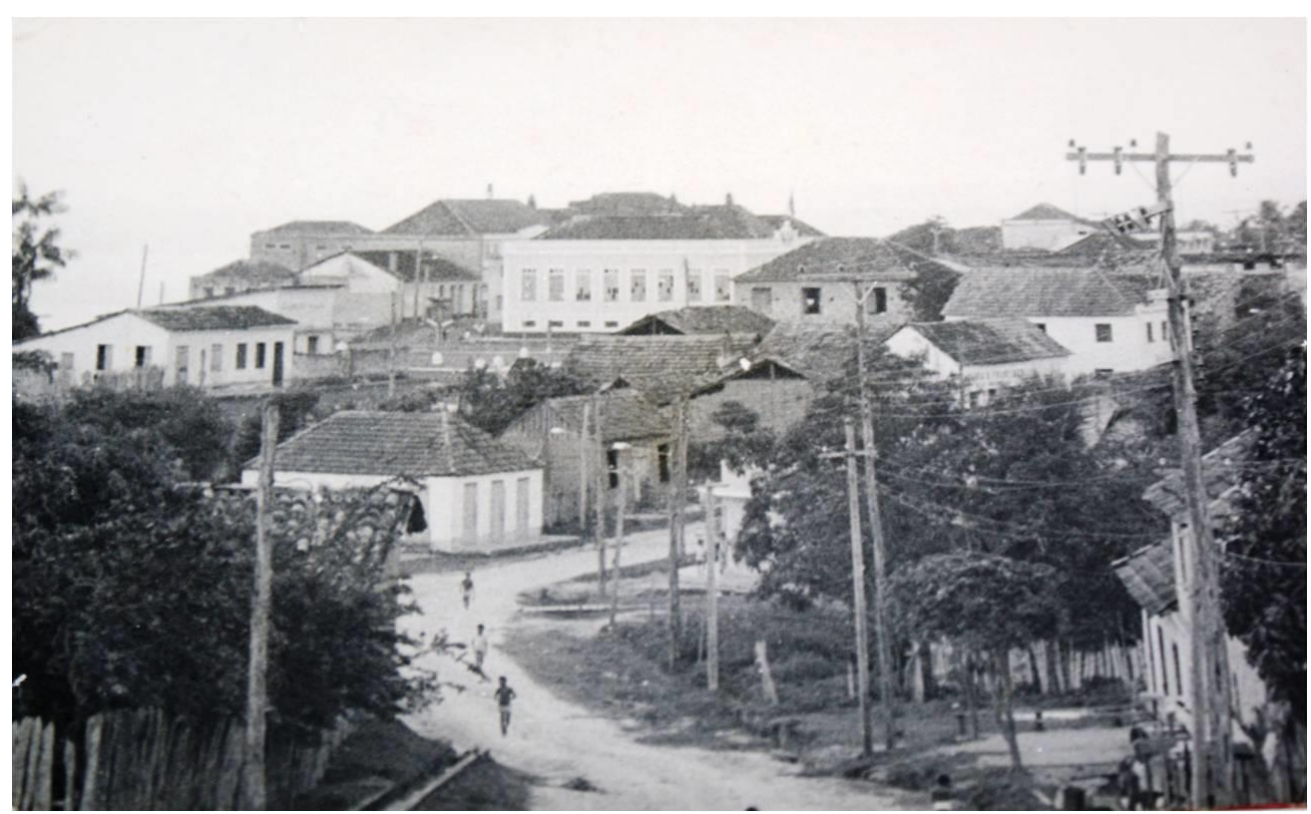

Imagem 4 - Tefé anos 60- Foto do Arquivo da Rádio Rural - Seção de documentação.

Tabela 1 - Município de Tefé e os domicílios anos 1960 e 1970

\begin{tabular}{|l|c|c|r|}
\hline \multicolumn{1}{|c|}{ Bairro } & $\begin{array}{c}\text { Casas } \\
\text { Alvenaria }\end{array}$ & Casas de Madeira & \multicolumn{1}{c|}{ Total } \\
\hline Monte Castelo & 142 & 246 & 388 \\
\hline Santo Antônio & 180 & 234 & 414 \\
\hline Olaria & 87 & 52 & 139 \\
\hline Juruá I e II & 590 & 310 & 900 \\
\hline Santa Rosa & 57 & 30 & 87 \\
\hline centro urbano & 483 & 131 & 614 \\
\hline Abial & 406 & 499 & 905 \\
\hline Jerusalém & 140 & 98 & 238 \\
\hline Santa Teresa & 140 & 220 & 360 \\
\hline Total & $\mathbf{2 2 2 5}$ & $\mathbf{1 8 2 0}$ & $\mathbf{4 0 4 5}$ \\
\hline
\end{tabular}

Fonte IBGE: Elaborados pela autora.

De acordo com os dados da Tabela 1 podemos primeiramente observar as áreas e bairros que constituíam a cidade de Tefé no final dos anos de 1960 e 1970, onde observa-se a

\section{Fistomertias}


existência, de 4045 casas e uma predominância nas casas de alvenaria sobre as casas de madeira. Tal fato demonstra as transformações do espaço urbano de maneira não planejada.

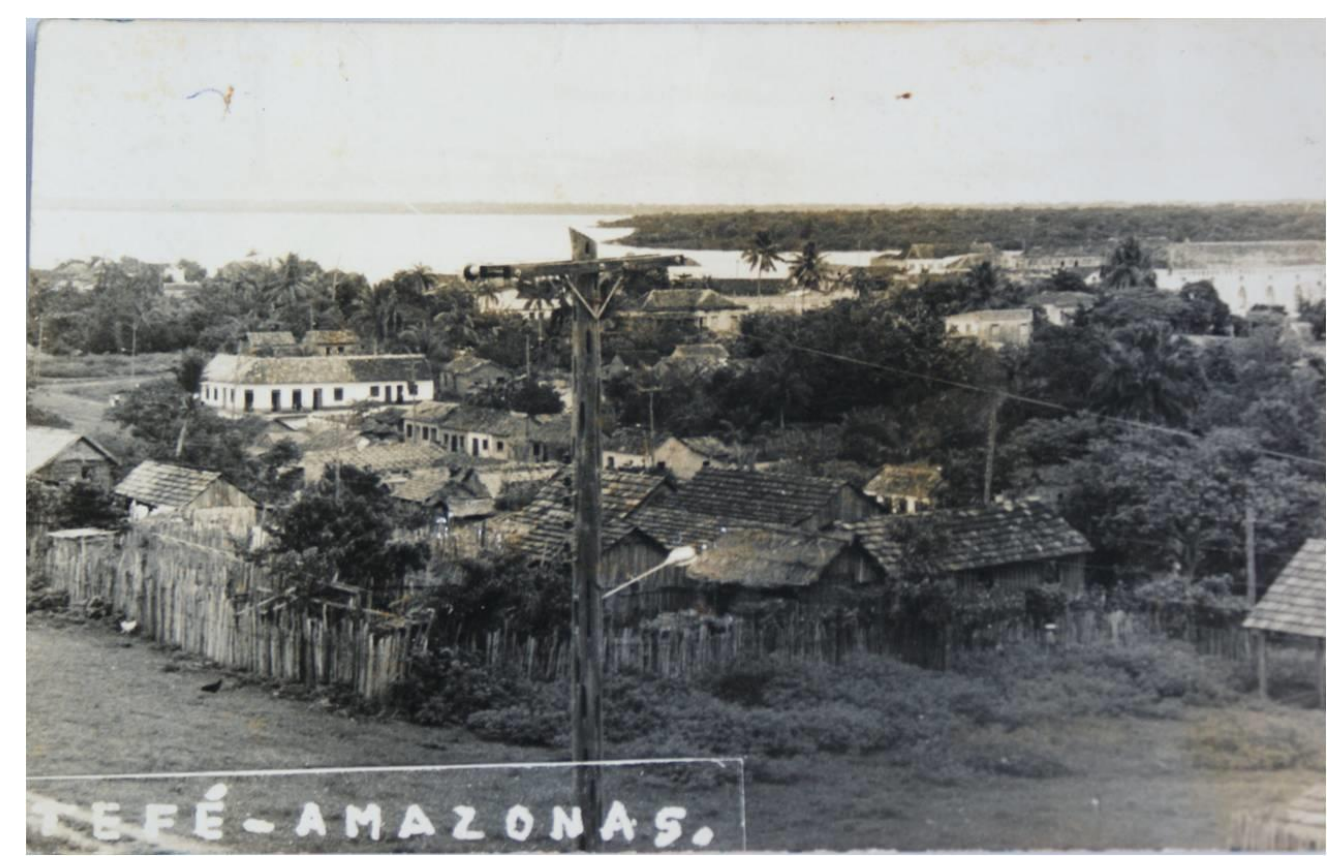

Imagem 5 - Tefé vista parcial anos 60 - Foto do Arquivo da Rádio Rural - Seção de documentação.

\section{Conclusão}

Falar da temática cidade atualmente requer uma aproximação com outras áreas das ciências sociais, notadamente a geografia, arquitetura ou sociologia. A discussão do que é uma cidade, portanto, é complexo para a história, apesar da existência da cidade e da discussão em si não ser nova. A História Cultural notadamente a partir da fundação da Revista dos Analles em 1929 observa-se a mudança de perspectiva de uma história narrativa para uma história problema. Notável contribuição da corrente dos Analles se constitui em relação ao alargamento do conceito de fonte (de monumento para documento, do privilégio das fontes escritas, para o uso de qualquer fonte). Nestes contextos insere-se o uso das fotografias como fonte para a disciplina história.

As informações a respeito da cidade de Tefé encontram-se dispersas em locais fora da mesma e o levantamento bibliográfico diretamente vinculado a uma história do lugar esbarra

\section{Fisistororias}


na escassez de fontes, documentos primários destruídos ou mesmo que não são mais disponíveis a sociedade.

Observamos que a maioria dos bairros atuais da cidade formaram-se no final dos anos de 1960 e início dos anos 1970, principalmente constituídos de pessoas oriundas de áreas distantes do interior do Estado do Amazonas e que fugiam das adversidades de seus locais de origem. A cidade cresceu, bairros, quarteirões, casas, disputando espaço de maneira desordenada e contanto com pouca estrutura por parte do poder público, seja na coleta de lixo, limpeza de ruas, fornecimento de água ou energia elétrica. Apesar disso observa-se as mudanças do espaço urbano, seja na verticalização das casas de bairros relevantes como o centro urbano, Juruá I e II dentre outros.

As imagens, fotografias presentes e utilizadas neste trabalho encontram-se no arquivo da rádio rural, em sua seção de documentação e retratam estas mudanças ocorridas na cidade, além de seus símbolos arquitetônicos mais presentes na memória de seus cidadãos, observa-se a não urgência no trato de prédios públicos antigos, fato que corrói com o tempo o patrimônio histórico da cidade.

Apesar de tudo, Tefé como é chamada de maneira carinhosa por seus citadinos é a princesinha do Solimões, recebe uma diversidade de pessoas de lugares variados e vive as margens do lago de mesmo nome, com suas marcas do passado, sua história ímpar e seus problemas crônicos. Este artigo visa resgatar parte desta memória presente nas imagens e discutir um pouco da relevância destas transformações do espaço urbano a luz de um tipo de fonte diferente notadamente as fotografias.

\section{Referências bibliográficas}

ALBURQERQUE, Marli Brito M. Pesquisando a fotografia como fonte histórica. In: Cadernos de Saúde Pública RJ, 3 (3): 297 - 305, jul/set, 1987.

BRESCIANI, Maria Stella. Cidade e História. In: OLIVEIRA, Lúcia Lippi. Cidade: História e Desafios. Rio de Janeiro: Editora FGV, 2002.

CHARTIER, Roger. O mundo como representação. Estudos avançados. São Paulo, IEA, VII, n. 5, p. 173-1991, 1991.

LIMA, Solange Ferraz e CARVALHO, Vania Correio. Usos sociais e historiográficos. In: O historiador e suas fontes. 1. Ed. São Paulo, 2012.

MAUD, Ana Maria e Lopes, Marcos Felipe de Brun. História e imagem: iconologia/icnografia e além. In: Novos domínios da História. Rio de Janeiro: Elsevier 2012.

\section{Filstortias}


MAUD, Ana Maria. Revista tempo: Através da imagem: fotografia e História interfaces. Rio de Janeiro, vol. 1 n.2, 1996.

MENEZES, Ulpiano T. Bezzara. História e imagem: iconologia/icnografia e além. In: Novos domínios da História. Rio de Janeiro: Elsevier 2012.

PESAVENTO, Sandra Jatahy. Muito além do Espaço: por uma História Cultural do urbano. Estudos Históricos. Rio de Janeiro, vol 8, n. 16, 1995, p. 279-290.

. História \& História Cultural- 3.ed.- Belo Horizonte: Autêntica, 2012.

PESSOA, Protásio Lopes. I ${ }^{\circ}$ centenário dos espiritanos em Tefé (síntese histórica). $1^{\text {a } e d . ~ M a n a u s: ~ I m p r e n s a ~}$ Oficial do Estado, 1997.

Tempo Ltda, 2005.

. História da Missão de Santa Teresa Dávila dos Tupebas - Tefé. Manaus: Editora Novo

QUEIROZ, Kristian Oliveira de. Centralidade periférica e integração relativizada: uma leitura de Tefé no Amazonas. 2015. 325f. Tese (Doutorado). Faculdade de Filosofia, Letras e Ciência Humanas, Universidade de São Paulo, São Paulo, 2015.

SCHAEKEN, Raimunda Gil. Centenário da presença espiritana na Prelazia de Tefé-AM (1897-1997), ManausAM, 1997 